
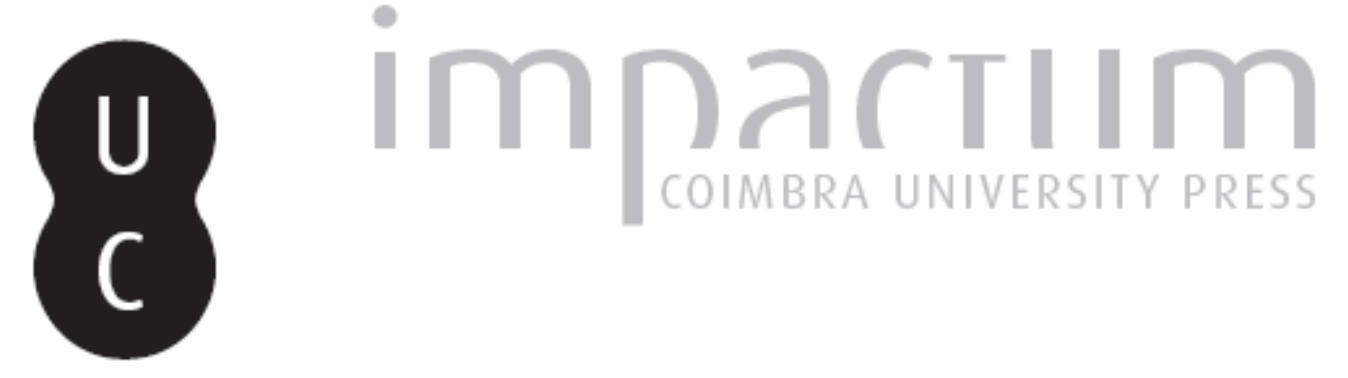

\title{
Contributos para o estudo da cerâmica foceense tardia ("Late Roman C Ware") no Municipium Olisiponense: sua representatividade no contexto peninsular
}

\author{
Autor(es): $\quad$ Sousa, Élvio Melim de \\ Publicado por: Imprensa da Universidade de Coimbra \\ URL \\ persistente: \\ URI:http://hdl.handle.net/10316.2/45362 \\ DOI: \\ DOI:https://dx.doi.org/10.14195/1647-8657_40_6
}

Accessed : $\quad$ 26-Apr-2023 11:23:35

A navegação consulta e descarregamento dos títulos inseridos nas Bibliotecas Digitais UC Digitalis, UC Pombalina e UC Impactum, pressupõem a aceitação plena e sem reservas dos Termos e Condições de Uso destas Bibliotecas Digitais, disponíveis em https://digitalis.uc.pt/pt-pt/termos.

Conforme exposto nos referidos Termos e Condições de Uso, o descarregamento de títulos de acesso restrito requer uma licença válida de autorização devendo o utilizador aceder ao(s) documento(s) a partir de um endereço de IP da instituição detentora da supramencionada licença.

Ao utilizador é apenas permitido o descarregamento para uso pessoal, pelo que o emprego do(s) título(s) descarregado(s) para outro fim, designadamente comercial, carece de autorização do respetivo autor ou editor da obra.

Na medida em que todas as obras da UC Digitalis se encontram protegidas pelo Código do Direito de Autor e Direitos Conexos e demais legislação aplicável, toda a cópia, parcial ou total, deste documento, nos casos em que é legalmente admitida, deverá conter ou fazer-se acompanhar por este aviso.

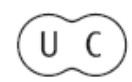


UNIVERSIDADE DE COIMBRA

FACULDADE DE LETRAS

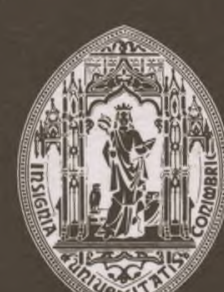

CONIMBRIGA

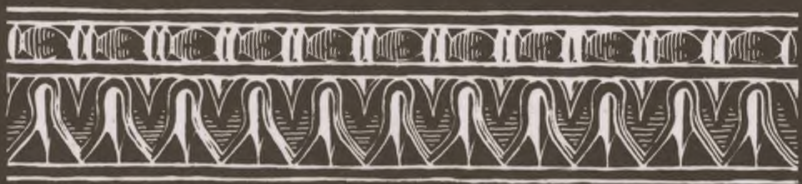

VOLUME XL - 2001 
Élvio Melim de Sousa

Conservador dos Museus da Câmara Municipal de Sintra, Arqueólogo

CONTRIBUTOS PARA O ESTUDO DA CERÂMICA FOCEENSE TARDIA

("LATE ROMAN C WARE") NO MUNICIPIUM OLISIPONENSE.

SUA REPRESENT ATIVIDADE NO CONTEXTO PENINSULAR

“Conimbriga" XL (2001) p. 201-226

RESUMO: Estuda-se, no presente trabalho, uma colecção de 31 fragmentos de Cerâmica Foceense Tardia ("Late Roman C Ware"), proveniente de quatro estações arqueológicas do Concelho de Sintra, e conservada, actualmente, no Museu Arqueológico de São Miguel de Odrinhas.

Estas estações encontram-se localizadas no Municipium Olisiponense, tal como outras seis que forneceram este tipo cerâmico, revelando uma demarcação e individualização claras deste território, justificadas pela importância de Olisipo e do seu porto.

ABSTRACT: In this paper 31 pieces of Late Roman C Ware are studied. All of the shreds belong to four archaeological sites within the limits of the Concelho de Sintra, and actually kept in the reserves of the Archaeological Museum of São Miguel de Odrinhas.

These four sites as well other six that provided similar ware were located in the Municipium Olisiponense and they show a clear individuality of this territorium, proving the importance of Olisipo and its harbour.

Conimbriga, $A O$ (2001) 199-224 
(Página deixada propositadamente em branco) 


\section{CONTRIBUTOS PARA O ESTUDO DA CERÂMICA FOCEENSE TARDIA ("LATE ROMAN C WARE”) NO MUNICIPIUM OLISIPONENSE. SUA REPRESENTATIVIDADE NO CONTEXTO PENINSULAR}

\section{Dispersão Geográfica e Quantitativos de Peças}

A produção denominada "Late Roman C Ware" consiste num fabrico cerámico peculiar que começou a ser difundido somente a partir do século IV d. C., desde o extremo Mediterráneo Oriental (Fócia). O seu aparecimento encontra-se registado em muito poucos locais da Península Ibérica, constituindo os seus achados, por essa razão, seguros indicadores da existência de contactos comerciais entre esses lugares e aquela região.

Afigura-se-nos, no entanto, provável, que esta cerâmica possua uma densidade e dispersão muito superiores às que lhe vêm sendo atribuídas, não só por ter vindo, em muitas estações, a ser confundida com fabricos diferentes, como também, e sobretudo, pelo facto de ser cada vez maior o número de locais onde vem sendo exumada a Sigillata Foceense Tardia.

O conjunto que ora nos propomos estudar inclui 31 fragmentos, provenientes de quatro de dez arqueo-sitios que forneceram Cerâmica Foceense Tardia, e que se inserem numa mesma área geográfica Municipium Olisiponense -, o que lhe confere uma representatividade relativamente significativa, dado o total de estações com este tipo de cerâmica, não ultrapassar, no actual território português, as $37^{1}$, advindo daqui o interesse da sua análise comparativa.

' M. G. P. MAIA, em 1978, identifica 9 locais no seu mapa de distribuição. Este número, pelos vários contributos posteriores de M. DeLGADO, em 1988 e 1992, foi

Conimbriga, 40 (2001) 199-224 
As 31 peças encontradas em intervenções arqueológicas realizadas no concelho de Sintra proporcionaram a seguinte distribuição: 23 fragmentos exumados na Villa de Santo André de Almoçageme (Colares, Sintra); 5 fragmentos recolhidos na Villa de Cabanas (São Marcos, Cacém, Sintra) ${ }^{*}$; 1 fragmento detectado em Armês (Terrugem, Sintra); e 2 fragmentos achados na Villa do Casal de Colaride (Cacém, Sintra).

Para além das estações sintrenses referidas, temos ainda conhecimento da existência, no território do Municipium de Olisipo, de 1 fragmento recolhido na Villa da Aldeia do Penedo (Runa, Torres Vedras) ${ }^{3}$; de 2 fragmentos encontrados no Alto do Cidreira (Carrascal de Alvide, Cascais)4; de alguns outros provenientes da Villa de Freiría (São Domingos de Rana, Cascais) $)^{5}$; de fragmentos exumados no Casal do Clérigo (Cascais) ${ }^{6}$; de 2 fragmentos achados nas escavações da Villa da Quinta da Bolacha (Falagueira-Venda Nova, Amadora) ${ }^{7}$; e de vários exemplares resultantes das escavações efectuadas na Rua dos Correeiros, no Teatro Romano e no Claustro da Sé, em Lisboa ${ }^{8}$.

Em Portugal, são conhecidas, ao todo, segundo sabemos (com base na bibliografia disponível e em algumas informações que nos

elevado para 20. A. M. Dias Diogo e L. TRINDADE, em trabalho recente (1999), apontam 24 locais diferentes, não especificando, ainda assim, as estações do concelho do Alvito que dizem existir (p. 86). Hoje, contudo, conhecem-se, pelo menos, um total de 37 (?) estações onde, entre nós, foi já encontrada Cerâmica Foceense Tardia.

2 Um destes 5 fragmentos encontra-se já publicado por M. G. P. MAIA, 1978, p. 301 e p. 306, Ests. II, n. ${ }^{\circ} 1$ e III. Referido por J. C. RIBEIRO, passim, no prelo; por M. Delgado, 1988, p. 45 e Est. II. e ainda por M. Beltrán Lloris, 1990, p. 280, Fig. 128; por A. ARRUdA, 1993, p. 308; por J. A. GonÇALVES GUIMARÃES, 1995, p. 181 e por A. M. Dias Diogo e L. TRindade, 1999, p. 85, fig. 2.

3 E. Sepúlveda, E. M. Sousa e V. Sousa, passim, no prelo.

${ }_{4}^{4}$ J. Nolen, 1988, p. 87, Est. IV; M. Delgado, 1988, p. 45 e Est. II; A. M. Dias

Diogo e L. TRINDADE, 1999, p. 85, fig. 2.

5 Informação amavelmente cedida pelo Professor Doutor José d'EnCARnAçÃo, a quem agradecemos; confrontar, a nível do contexto cronológico da estação, G. Cardoso e J. d'Encarnação, 1998, p. 181.

6 Informação cedida gentilmente pelo Dr. Guilherme CARDoso, a quem se agradece.

7 J. A. MiRanda, 1998, p. 19; J. A. Miranda et alii, 1999, p. 4.

8 Rua dos Correeiros e Claustro da Sé: informação cedida cordialmente pelo Dr. Cíementino AMARo (a quem agradecemos); Teatro Romano de Lisboa: A. M. DIAS Diogo e L. Trindade, 1999, pp. 85-86 e fig. 2; A. ARRUdA, 1993, p. 308.

Conimbriga, 40 (2001) 199-224 
foram gentilmente cedidas), 37 estações que forneceram "Late Roman C Ware" 9;

\author{
1 - Bracara Augusta ${ }^{9} 1011$ \\ 2 - Falperra (Nogueira, Braga) ${ }^{11}$; \\ 3 - São Mamede de Recezinhos (Penafiel) ${ }^{12}$; \\ 4 - Freixo (Marco de Canavezes) ${ }^{13}$; \\ 5 - Portus (Casa do Infante) ${ }^{14}$; \\ 6 - Cale (Vila Nova de Gaia) ${ }^{15}$; \\ 7 - Conimbriga ${ }^{16}$
}

9 É bem provável que o número de estações que forneceram Cerâmica Foceense Tardia seja maior. Na bibliografia consultada, todavia, apenas identificámos estes arqueo-sítios. Ainda assim, torna-se erróneo precisar, com maior exactidão, este número (37), porquanto A. M. Dias Diogo e L. Trindade (1999, p. 86) não quantificarem, ou identificarem, as várias estações do concelho de $\mathrm{Al}$ vito (Beja) que mencionam.

10 Bracara Augusta: A. M. Alarcão, 1966, pp. 45-50; Dez Anos de Actividade Arqueológica em Portugal 1960-1970,1971, Coimbra, pp.32e33;J.W. HAYES, 1972, p. 415, nota 5 e Apêndice I, p. 460, Mapa 15; J. AlarCÃo, 1974, p. 152, foto 78 e p. 265; M. G. P. MaiA, 1974, p. 334; M. Delgado, 1988, p. 45 e Est. II; M. Beltrán Lloris, 1990, p. 280, Fig. 128; Paz Peralta, 1991, p. 223; M. Delgado, 1992, p. 125; A. ARruda, 1993, p. 308; J. A. Gonçalves Guimarães, 1995, p. 181; A. M. Dias Diogo e L. Trindade, 1999, p. 85, fig. 2; J. A. Gonçalves Guimarães e C. T. Pinto, no prelo, Cap. II, C-2.2.3, penúltimo parágrafo.

${ }^{11}$ Falperra (Nogueira, Braga): M. Delgado, 1988, p. 45 e Est. II; A. M. Dias

Diogo e L. TRINDADE, 1999, p. 85, fig. 2.

12 São Mamede de Recezinhos (Penafiel): T. SoElRo, 1985-86, pp. 15-32, sobretudo p. 20 e Fig. 5, n. ${ }^{\circ}$ 2; M. Delgado, 1988, p. 45 e Est. II; A. M. Dias Diogo e L. TRINDADE, 1999, p. 85, fig. 2.

${ }_{13}$ Freixo (Marco de Canavezes): M. Delgado, 1988, p. 45 e Est. II; A. M. DiAS

Diogo e L. TRINDADE, 1999, p. 85, fig. 2.

14 J. A. Gonçalves Guimarães e C. T. Pinto, no prelo, Cap. II, C-2.2.3, penúltimo parágrafo. Agradecemos ao Dr. J. A. Gonçalves GuImARÃEs a preciosa ajuda que nos deu, bem como a bibliografia que nos endereçou acerca de Portus e, sobretudo, de Cale.

15 Cale (Vila Nova de Gaia): J. A. Gonçalves Guimarães, 1992, p. 109; J. A. Gonçalves Guimarães, 1993,passim; J. A. Gonçalves Guimarães, 1995, pp. 179181, Quadros V e VI e Est. XXII; J. A. Gonçalves Guimarães e C. T. Pinto, no prelo, Cap. III, C-2.2.3.

16 Conimbriga: Dez Anos de Actividade Arqueológica em Portugal, 1971, Coimbra, p. 33; M. G. P. MaIA, 1974, p. 334; M. Delgado, 1975 A, pp. 151-152 e Pl. XII; M. Delgado, 1975 B, pp. 285-291, 308-311 e p. 334; P.-A. FÉVRIER, 1976, p. 64 


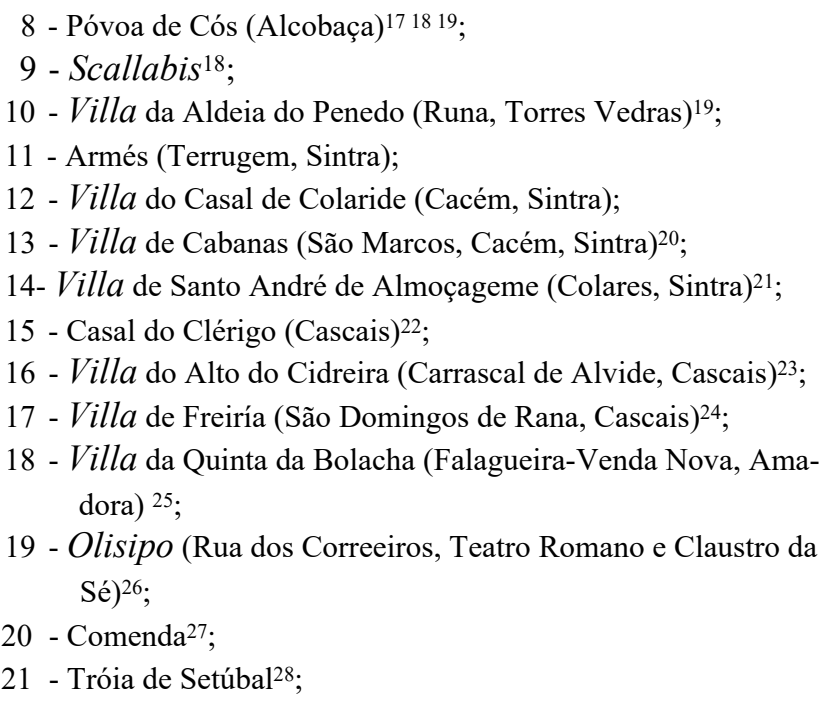

e pp. 70-72; M. G. P. MaiA, 1978, pp. 300 e 307, Est. Ill; F. MAYeT e M. Picon, 1986, pp. 130 e 131, Fig. 1;M. Delgado, 1988, p. 45 e Est. II; M. Beltrán Floris, 1990, p. 280, Fig. 128; Paz Peralta, 1991, p. 223; M. Delgado, 1992, p. 127 e 129; A. Arruda, 1993, p. 308; J. A. GonÇAlves Guimarães, 1995, p. 181; A. M. Dias Diogo e L. Trindade, 1999, p. 85, fig. 2; J. A. Gonçalves Guimarães e C. T. Pinto, no prelo, Cap. II, C-2.2.3, penúltimo parágrafo.

${ }_{17}$ Póvoa de Cós (Alcobaça): M. Delgado, 1988, p. 45 e Est. II; A. M. Dias

Diogo e L. TRINDADE, 1999, p. 85, fig. 2.

18 Scallabis: A. M. Dias DiOGO, 1984, pp. 111-141 e Ests. I a VI; A. M. DiAS

Diogo e L. TRINDADE, 1999, p. 85, fig. 2.

19 Cf. supra, nota 3.

20 Cf. supra, nota 2.

${ }_{21}$ E.M. SousA, 1989, pp. 85-91.

22 Cf. supra, nota 6.

${ }^{23}$ Cf. supra, nota 4.

${ }^{24}$ Cf. supra, nota 5.

${ }_{25}$ Cf. supra, nota 7.

${ }_{26}$ Cf supra, nota 8.

27 L. Trindade e A. M. Dias Diogo, 1996, pp. 7-12; A. M. Dias Diogo e L.

TRINDADE, 1999, p. 85, fig. 2.

28 Tróia de Setúbal: M G. P. MAIA, 1974, pp. 333-34 e Est. I a IV; M. G. P. MAIA, 1978, pp. 300 e 307, Est. Ill; J. W. HAYES, 1980, p. 525, nota 5; F. MAYET e M. Picon, 1986, pp. 130-131, Fig. 1; M. Delgado, 1988, p. 45 e Est. II; M. BeltráN Lloris, 1990, p. 280, Fig. 128; M. Delgado, 1992, p. 127; F. MAYet, 1994, p. 47 e Fig. 29, n. 119-121; A. Arruda, 1993, p. 308; J. A. GonÇAlves Guimarães, 1995, 


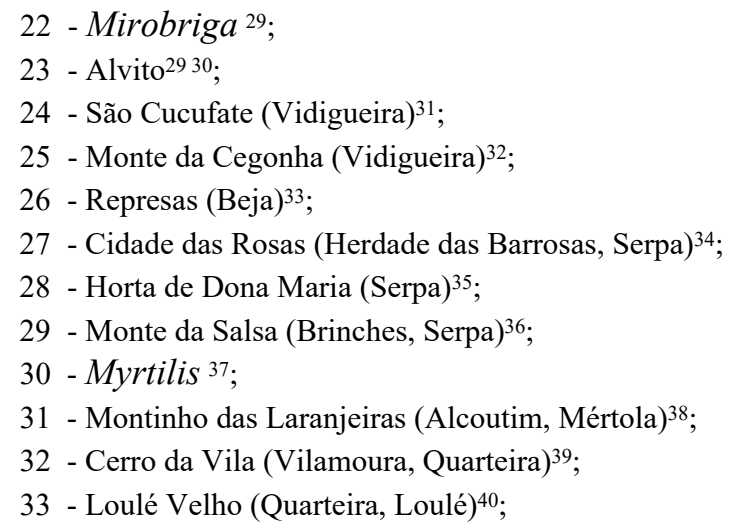

p. 181; A. M. Dias Diogo e L. Trindade, 1999, p. 85, fig. 2; J. A. Gonçalves GuimaRÃES e C. T. Pinto, no prelo, Cap. II, C-2.2.3, penúltimo parágrafo.

29 Mirobriga: M. Delgado, 1988. p. 45 e Est. II; A. M. Dias Diogo e L. Trin-

DADE, 1999, p. 85, fig. 2; QuARESMA, J. C., 1999, p. 72 e 80.

30 "Estações do concelho de Alvito": A. M. Dias Dıogo e L. TRINDADE, 1999, p. 86.

31 São Cucufate (Vidigueira): M. Delgado, 1988, p. 45 e Est. II; F. MAYET, et alii, 1990 , pp. 48-50,248,251,265 e Grav. n. ${ }^{\circ}$ 437; A. M. DiAS Diogo e L. TRINDADE, 1999 , p. 85 , fig. 2.

32 Monte da Cegonha (Vidigueira): M. Delgado, 1988, p. 45 e Est. II; A. M.

Dias Diogo e L. TRINDADE, 1999, p. 85, fig. 2.

${ }_{33}$ Represas (Beja): M. G. P. MAIA, 1978, p. 300; M. Delgado, 1988, p. 45 e Est.

II; A. M. Dias Diogo e L. TRINDADE, 1999, p. 85, fig. 2.

34 Cidade das Rosas (Herdade das Barrosas, Serpa): M. G. P. MAIA, 1978, p. 301

e Est. II, 2; M. Delgado, 1988, p. 45 e Est. II; M. Beltán Lloris, 1990, p. 280, Fig. 128; A. ARrudA, 1993, p. 308; A. M. Dias Diogo e L. Trindade, 1999, p. 85, fig. 2.

35 Horta de Dona María (Serpa): M. G. P. MAIA, 1978, p. 301 e Est. II, 3; M. Delgado, 1988, p. 45 e Est. II; A. Arruda, 1993, p. 308; A. M. Dias Diogo e L. TRINDADE, 1999, p. 85 , fig. 2.

${ }^{36}$ Monte da Salsa (Brinches, Serpa): J-G. Gorges, 1979, pp. 473 e 474.

37 Myrtilis: M. Delgado, 1988, p. 45 e Est. II; M. Delgado, 1992, pp. 125-133; V. LoPES, 1993, p. 87; A. ARrudA, 1993, p. 308; J. A. GonÇAlves GuimarÃES, 1995, p. 181; A. M. Dias Diogo e L. TRINDADE, 1999, p. 85, fig. 2.

${ }_{38}$ Montinho das Laranjeiras (Alcoutim): H. CoutinHO, 1997, PP. 47-48; A. M.

Dias Diogo e L. TRINDAde, 1999, p. 85, fig. 2.

39 Cerro da Vila (Vilamoura, Quarteira): M. G. P. MAIA, 1978, pp. 302 e 307, Est. Ill; M. Delgado, 1988, p. 45 e Est. II; M. Delgado, 1992, p. 125; A. Arruda, 1993, p. 308; A. M. DiAS DIogo e L. TRINDADE, 1999, p. 85, fig. 2.

40 Loulé Velho (Quarteira, Loulé): M. G. P. MAIA, 1978, pp. 302 e 307, n. ${ }^{\circ} 10$ e 
34 - Foz do Arade (Portimão) ${ }^{*}$;

35 - Marim (Quelfes, Olhão) ${ }^{42}$;

36 - Balsa (Torre de Ares, Luz, Tavira) ${ }^{43}$;

37 - Boelhe (Penafiel).

$\mathrm{Na}$ área a Norte do Tejo, conhecemos 20 locais que forneceram "Late Roman C Ware" e que perfazem cerca de 54\% do total de estações inventariadas. A Sul do Tejo, os sítios onde já foi exumado este tipo cerâmico, somam um total de 17 , ou seja $46 \%$ do número global de estações inventariadas.

Todavia, este equilíbrio 'aparente', perde grande parte do seu significado quando, ao analisarmos a respectiva carta de distribuição, verificamos que cerca de $50 \%$ das estações localizadas na área $\mathrm{N}$ pertencem ao Municipium Olisiponense. Parece, então, evidente, a individualização deste Município, o qual, a nível económico e geográfico, se demarca claramente da restante área $\mathrm{N}$ em que se insere.

Se associarmos, por sua vez, Olisipo com a foz do Sado (Comenda e Tróia de Setúbal), obtemos um total de 12 estações, ou seja, cerca de $32 \%$ do total de estações inventariadas entre nós (território actualmente português) para uma única região, isto é, uma percentagem invulgar que terá de ser, quanto a nós, forçosamente explicada pela implantação e área de influência do porto de Olisipo.

Outro dado que devemos ter em linha de conta, é o facto de não podermos relacionar a densidade dos achados desta cerâmica apenas e unicamente com a extensão da área escavada por estação, se bem que se tenha que ter em consideração esse factor para o caso de Conimbriga, porquanto a Villa de Cabanas (São Marcos, Cacém, Sintra),

208; M. Delgado, 1988, p. 45 e Est. II; M. Beltrán Lloris, 1990, p. 280, Fig. 128; A. Arruda, 1993, p. 308; J. A. Gonçalves Guimarães, 1995, p. 181; A. M. Dias Diogo e L. Trindade, 1999, p. 85, fig. 2; J. A. Gonçalves Guimarães e C. T. Pinto, no prelo, Cap. II, C-2.2.3, penúltimo parágrafo.

${ }_{41}$ Foz do Arade (Portimão): C. TAVARES DA Silva, A. Coelho-SoAres e J.

SOARES, 1987, pp. 203-219, sobretudo pp. 203, 207 - nº 10 e 208.

42 Marim (Quelfes, Olhão): M. G. P. MAIA, 1978, pp. 302 e 307, Est. Ill; M. Delgado, 1988, p. 45 e Est. II; M. Beltrán Lloris, 1990, p. 280, Fig. 128; A. Arruda, 1993, p. 308; J. A. GonÇalves Guimarães, 1995, p. 181; A. M. Dias Diogo e L. TRINDADE, 1999, p. 85, fig. 2; J. A. GonÇALVES GuimarãES e C. T. Pinto, no prelo, Cap. II, C-2.2.3, penúltimo parágrafo.

43 Balsa (Torre de Ares, Luz, Tavira): M. Delgado, 1988, p. 45 e Est. II; J. U. S. Nolen, 1994, pp. 102 e 221; A. M. Dias DiogO e L. TRINDADE, 1999, p. 85, fig. 2. 
somente em recolhas de superfície e em algumas sondagens, forneceu 5 fragmentos, e a Villa de Santo André de Almoçageme (Colares, Sintra), apenas em cerca de $2500 \mathrm{~m} 2$ de área escavada, forneceu 23 fragmentos. Em contrapartida, Tróia de Setúbal e Myrtilis, incomparáveis a Santo André de Almoçageme e a Cabanas em área já escavada, não forneceram, ao que se sabe, mais do que $23^{44} 45$ e 29 exemplares, respectivamente.

Esta proporção relativa dos achados parece, pois, revelar uma realidade histórica e não, como à partida poderíamos supor, um resultado fortuito e relacionado apenas com as densidades de exploração.

Algo comum a todas estas estações, onde se descobriram fragmentos de Sigillata Foceense Tardia, parece ser a relativa localização em zonas litorais (ou de fácil contacto com o mar, através de boas vias fluviais navegáveis) e florescentes do ponto de vista económico, panorâmica que podemos também observar quanto aos fragmentos detectados em Espanha, onde surgem, v. g., em Emporion ${ }^{45}$, em Formentera 464748 49, em Barcino , em Pollentia ${ }^{48}$, em Tarraco ${ }^{49}$, em Baelo 5051 52, em Lucentum 51, em Carthago Nova 52, em Maiorca ${ }^{53}$, no Cerro de Montroy ${ }^{54}$, em Cártama ${ }^{55}{ }^{56}$ e em Carteia $^{56}$, entre outras.

44 Onze fragmentos publicados por M. G. P. MAIA (1974) e doze fragmentos publicados por F. MAYET (1994).

45 J. W. HAYES, 1972, p. 415, nota 5; M. G. P. MAIA, 1974, p. 334.

46 Cf. nota anterior.

47 Cf. supra, nota 45.

48 J. W. HAYES, 1972, p. 415, nota 5 e p. 460, Mapa 15; M. G. P. MAIA, 1974, p. 334 .

49 Cf. nota anterior; M. BeLtRÁn LLORIS, 1990, p. 280, Fig. 128.

50 M. Delgado, 1975 A, p. 286, nota 11; M. Delgado, 1975 B, p. 83 (intervenção de F. MAYET na discussão sobre a "Late Roman C Ware" de Conimbriga)। M. Beltrán LloRIS, 1990, p. 280, Fig. 128; F. MAYet, 1991, pp. 373-376 e Pis. CXVI aCXX.

${ }_{51}$ P. ReYNoLDS, 1987, pp. 109-121.

52 R. MÉndeZ OrTiz, 1984, pp. 147-156 e Láms. 1 e 2; M. BeltrÁn Lloris, 1990, p. 280, Fig. 128.

53 F. MAYet e M. Picon, 1986, pp. 129-143.

54 F. MAYet e M. Picon, 1986, pp. 129-143; M. BeltrÁn LloRIS, 1990, p. 280,

Fig. 128.

${ }_{55} \mathrm{Cf}$. nota anterior.

56 Cf. supra, nota 54.

Conimbriga, 40 (2001) 199-224 
Tal facto leva-nos a aceitar, como já vem sendo habitual, uma difusão quase exclusivamente marítima deste fabrico, através dos grandes portos da Península Ibérica, abrangendo apenas alguns pontos interiores 57 , servidos sempre por grandes vias fluviais ou por importantes rotas viárias dos arredores dos principais centros urbanos - como é o caso de nove das dez estações do Municipium Olisiponense num movimento aparentemente independente dos acontecimentos político-militares e, talvez mesmo, religiosos, da época - influências suevas e bizantinas ${ }^{58}$.

Assim, cremos que indicará, provavelmente, mais o continuar de tradições antigas, que desde há séculos uniam esses pontos da Península ao Mediterrâneo Oriental, quer a nível comercial quer, inclusive e aparentemente a nível demográfico.

De facto, em todas as regiões onde se detectou a existência de um outro tipo de cerâmica, também oriental (ou de tradição oriental), se bem que muito anterior - a Cerâmica Vidrada Romana ${ }^{59}$, difundida essencialmente durante e a partir do séc. I d. C. -, foi já descoberta a existência de achados de "Late Roman C Ware". Além disso, em algumas destas regiões, revelou-se muito forte o elemento de cariz orientalizante na onomástica.

Temos, pois, deste modo, verificada a existência de Cerâmica Vidrada Romana em Conimbriga ${ }^{60}$, em Tróia de Setúbal ${ }^{61}$, no Municipium Olisiponense ${ }^{62}$, e no Conventus Pacensis, precisamente em

57 Em Espanha, o panorama é idêntico, constituindo o caso de Caesaraugusta o ponto mais afastado da costa (PAz Peralta, 1991, p. 223).

58 Confrontar, a este respeito, M. G. P. MAIA, 1978, pp. 302.

59 Embora de produção originária do Mediterrâneo Oriental, existem, paralelamente, outros centros produtores, mais tardios, na Gália e na Península Itálica.

60 H. Comfort, 1961, p. 13; J. Alarcão, 1968, pp. 74 e 75; M. A. HortA Pereira, 1970, p. 53; M. A. G. Pereira, 1971, p. 146, nota 1; J. Alarcão, 1975, pp. 100-103 e PI. XVII, n. ${ }^{\circ}$ 7; J. Alarcão, 1976, pp. 39-42 e PI. XXXII; A. J. F. QUINTEIRA, 1984, pp. 104-110.

61 M. A. G. Pereira, 1971, pp. 145-154; J. Alarcão, 1976, p. 41; E. M. SousA, 1993-1994, pp. 359-369.

62 M. A. Horta Pereira, 1970, pp. 49-52 e Ests. I e II; M. A. G. Pereira, 1971, p. 146, nota 1; J. ALARCÃo, 1976, p. 41; J. C. RibeIRo, no prelo. 
Alcácer do Sal63 e na Região de Beja - Lobeira Grande ${ }^{64}$ e Rio de Moinhos (Aljustrel) ${ }^{65}$.

Por outro lado, na onomástica, Conimbriga apresenta, no total, uma percentagem de cerca de $10 \%$ de antropónimos de cariz orientalizante ${ }^{66}$, Tróia de Setúbal uma "relativa abundância de antropónimos etimológicamente gregos" ${ }^{67}$, o Municipium Olisiponense uma percentagem de cerca de 10 a $15 \%$, se bem que para Olisipo (urbs) esses valores atinjam os $25 \%$ e somente $5 \%$ se nos limitarmos aos agn ${ }^{68}$, e o Conventus Pacensis uma percentagem de algo mais de $20 \%{ }^{69}$.

Em Espanha - e tendo em conta unicamente os locais que forneceram Sigillata Foceense Tardia -, para além do caso paradigmático de Emporion, de remotas e fortíssimas tradições orientais, confrontar, v. g., Tarraco, onde os elementos de cariz grecizante se cifram em cerca de $28 \%$ do total $^{70}$, ou seja, uma percentagem não muito díspar das referidas anteriormente.

Tais dados não são mais do que testemunhos de como a orla marítima peninsular estava, desde há muito, voltada essencialmente para o mundo mediterránico, Oriente inclusive.

\section{Formas e Cronologia}

As taças baixas de fundo com pé em anel e bordo saliente de perfil vertical (Forma Hayes 3 e variantes) apresentam-se-nos como as mais comuns, sendo consideradas, por tal facto, como "típicas" do fabrico da Cerámica Foceense Tardia e quase como a única forma pela qual a "Fate Roman C Ware" é detectada no Ocidente do Mediterráneo.

${ }_{63}$ Informação gentilmente cedida pelo Dr. A. M. DIAS DIOGO, a quem agradecemos.

${ }_{64}$ F. Nunes Ribeiro, 1957; M. A. G. Pereira, 1971, p. 146; J. Alarcão, 1976, p. 41 .

65 R. Freire de Andrade, 1963; M. J. Almagro Corbea, 1966-67, pp. 213-223; R. Freire de Andrade e O. Veiga Ferreira, 1967; J. Alarcão, 1968, pp. 74 e 75; M. A. G. Pereira, 1971, p. 146; J. Alarcão, 1976, p. 41.
66 J. C. RIBEIRO, no prelo.
67 J. d'EnCARNAÇÃo, 1984, pp. 15 a 17.
68 Cf. supra, nota 66.
69 Cf. nota anterior.
70 G. ALFõLdY, 1977, pp. 293-295.

Conimbriga, 40 (2001) 199-224 
Dos 31 fragmentos do Municipium Olisiponense que analisámos, 28 apresentam a característica Forma 3 de Hayes (e variantes). O n. ${ }^{\circ} 6$ do catálogo levanta, no entanto, algumas dúvidas quanto à sua classificação tipológica, podendo inserir-se, muito possivelmente, na Forma 1 de Hayes (variantes $\mathrm{C}$ ou $\mathrm{D}$ ). Quanto à peça $\mathrm{n}^{\circ}$ 31, integra-se, pelas suas peculiaridades, na Forma 5 (variante A) do mesmo autor. Por sua vez, o exemplar $\mathrm{n}^{\circ} 23$ parece integrar-se na Forma 6 de Hayes. Todos os fragmentos exumados no Alto do Cidreira (Carrascal de AI vide, Cascais) $)^{71}$ pertencem à Forma 3 , tal como os provenientes da Villa de Freiría (São Domingos de Rana, Cascais) ${ }^{72}$, do Casal do Clérigo (Cascais) ${ }^{73}$ e da Villa da Quinta da Bolacha (Falagueira-Venda Nova, Amadora) ${ }^{74}$. Na Villa da Aldeia do Penedo (Runa, Torres Vedras), o único fragmento detectado parece apresentar, muito provavelmente, a Forma 1 de Hayes $^{75}$.

$\mathrm{Na}$ restante área a Norte do Tejo, os exemplares de Braga integram-se nas Formas 3 e 5 de Hayes $^{76}$ e, em Conímbriga, segundo Manuela Delgado ${ }^{77}, 93 \%$ das peças que permitem reconstituição apresentam a característica Forma 3 (e variantes), contra apenas três únicos fragmentos pertencentes à Forma 5. Nos outros locais desta região, e com base nas informações patentes na bibliografia consultada, a Sigillata Foceense Tardia foi sempre detectada através da Forma 3 de Hayes (e variantes).

Entre os 20 fragmentos encontrados em Tróia de Setúbal ${ }^{78}$, pelo menos 12 peças apresentam a Forma 3 de Hayes (e variantes), contra apenas 8 fragmentos cujas formas não são passíveis de ser determinadas, ou, então, não se encontram referenciadas na bibliografia disponível.

Nos demais sítios insertos na área a Sul do $\mathrm{Tejo}^{79}$, todos os fragmentos até agora publicados pertencem à Forma 3 de Hayes (e

71 J. U. S. Nolen, 1988, p. 87, Est. IV; M. Delgado, 1988, p. 45 e Est. II; A. M. Dias Diogo e L. TRindade, 1999, p. 85, fig. 2.

72 Cf. supra, nota 5.

73 Cf. supra, nota 6.

74 Cf. supra, nota 7.

75 Cf. supra, nota 3.

${ }_{76}$ Cf. J. Alarcão, 1974, foto 78 e M. Delgado, 1988, p. 45 e Est. II.

77 M. Delgado, 1975A, pp. 286 e 287.

78 M. G. P. MAIA, 1974, pp. 335-340; F. MAYet, 1994, p. 47 e Fig. 29, n. ${ }^{\circ} 119-$ -121; M. Delgado, 1988, p. 45 e Est. II.

79 Todos os fragmentos apresentados por M. G. P. MAIA, em 1978, e provenien- 
variantes), à excepção de Myrtilis, onde, para além da predominância daquela forma, foi exumado, todavia, um fragmento atribuído à Forma 8 de Hayes ${ }^{80}$, do Cerro da Vila, onde ocorre a Forma $5^{81}$, e do Monte da Cegonha, onde se registou a Forma $2^{82}$.

Esta preponderância massiva da Forma 3 de Hayes (e variantes) leva-nos a concluir, como se obvia, ter sido este o modelo mais produzido e, consequentemente, o mais exportado de todo o fabrico. A. M. Dias Diogo e L. Trindade referem mesmo que a esta Forma poderá corresponder "cerca de $80 / 90 \%$ de toda a produção entre os meados do século Ve os meados do século VI" 83 .

Cronologicamente, todas as peças detectadas em Portugal, e até agora divulgadas, encontram-se balizadas, grosso modo, entre a segunda metade do século $\mathrm{V}$ d.C.e a primeira metade do século VI d. C., não se tendo registado, fora deste contexto temporal, nenhuma outra ocorrência. Ainda assim, julgamos ser de admitir o aparecimento de achados novos detentores de cronologia algo mais recuada, atendendo, sobretudo, às remotas (e contínuas) ligações entre a Península Ibérica e o Mediterrâneo Oriental.

Apesar desta análise comparativa ter sido elaborada a partir do estudo parcial (4 num conjunto de 10) das estações arqueológicas do Municipium Olisiponense onde foi identificado, até agora, este tipo cerâmico, na maior parte desses locais, apenas se efectuaram recolhas de superfície e/ou sondagens (Armés, Cabanas e Casal de Colaride), pelo que cremos que, futuramente, com novas pesquisas - ou continuação de anteriores -, muitos outros exemplares poderão ser detectados nesta região. O mesmo poder-se-á dizer para todo o país, sobretudo para o Sul, onde se localiza uma boa parte das estações onde foi já exumada "Late Roman C Ware", como ainda pela sua proximidade ao Mediterrâneo.

tes de estações localizadas a sul do Tejo, integram-se, tipológicamente, na Forma 3/ variantes de Hayes; M. Delgado, 1988, p. 45 e Est. II; A. M. Dias Diogo e L. TrinDADE, 1999, p. 85, fig. 2.

${ }^{80}$ M. DelgadO, 1992, p. 127, n. ${ }^{\circ} 11$ epp. 129-139.

81 Cf. nota anterior.

82 Cf. supra, nota 80.

83 A. M. Dias Diogo e L. TRindade, 1999, p. 85.

Conimbriga, 40 (2001) 199-224 
Estes factores não invalidam, porém, que os achados conhecidos possam, desde já, apontar o caminho certo - dentro da sua relatividade - quanto à sua distribuição geográfica preferencial e formas mais comuns do fabrico, pelo que reputamos pertinentes, ainda que forçosamente provisórias, saliente-se, as considerações por nós adiantadas nesta análise.

\section{CATÁlOGO:}

N. ${ }^{\circ} 1$ - MRS/SA/R/85/1075. Peça: fragmento de bordo de taça. Forma: Hayes 3/ variante C. Diâmetro: $228 \mathrm{~mm}$ (exterior). Pasta: laranja-amarelada, de tom escuro, de grão médio, porosa, com impurezas, dura e de fractura muito irregular. Engobe: externo/ laranja-acastanhado, de tom escuro, homogéneo, pouco espesso e sem brilho; interno/ laranja-acastanhado claro, de tom vivo, homogéneo, mais espesso que o externo e sem brilho. Decoração: apresenta cinco fieiras paralelas de incisões com acentuações diferentes, obtidas por meio de guilhoché. Cronologia: segunda metade do séc. V d.C. Proveniência: Villa de Santo André de Almoçageme, Quadrado II, 2a Camada.

N. 2 - MRS/SA/R/85/1768: Peça: fragmento de bordo de taça. Forma: Hayes 3/ variante C. Pasta: laranja-acastanhada escura, com uma mancha amarelada junto à parede externa, de grão médio, pouco porosa, com impurezas, dura, de fractura irregular. Engobe: externo/ / acastanhado escuro, com manchas de cor castanha muito escura com tons acinzentados, pouco espesso, sem brilho; interno/ laranja-avermelhado, de tom acastanhado, mais espesso que o externo, sem brilho. Cronologia: segunda metade do século V d.C. Proveniência: Villa de Santo André de Almoçageme, Quadrado VII, 2a Camada.

N. 3 - MRS/SA/R/86/1703. Peça: fragmento de bordo e parede de taça. Forma: Hayes 3/ variante C. Pasta: laranja-acastanhada, de tom escuro, de grão médio, pouco porosa, com impurezas, dura, de fractura irregular. Engobe: externo/ todo o bordo apresenta uma cor acastanhada escura, com laivos cinzentos mais ou menos acentuados até ao toro saliente em que termina o bordo, pouco espesso, pouco brilhante; a parede, por sua vez, apresenta uma cor laranja- 
-acastanhada, de tom vivo, com manchas de cozedura de torn mais claro; interno/ laranja-acastanhado, de tom vivo, homogéneo, pouco espesso, sem brilho. Cronologia: segunda metade do século V d.C. Proveniência: Villa de Santo André de Almoçageme, Testemunho entre os Quadrados VI/VII e XI/XII, 2a Camada.

N. ${ }^{\circ} 4$ - MRS/SA/R/85/1980. Peça: fragmento de fundo de taça com pé em anel. Forma: Hayes 3/ variante D. Diâmetro: $128 \mathrm{~mm}$ (interior, ao nível do anel). Pasta: castanha alaranjada, de tom ligeiramente escuro, de grão fino, depurada, pouco porosa, dura, de fractura irregular. Engobe: externo/ laranja-acastanhado escuro, espesso, brilhante; interno/ idêntico ao externo. Cronologia: finais do século V d.C./ inícios do século VI d.C. Proveniência: Villa de Santo André de Almoçageme, Quadrado VII, 2a Camada.

N. ${ }^{\circ} 5$ - MRS/SA/R/86/I998. Peça: fragmento de bordo de taça. Forma: Hayes 3/ provavelmente variante C. Diâmetro: $257 \mathrm{~mm}$ (exterior). Pasta: laranja-acastanhada clara, de grão médio, porosa, com impurezas visíveis, dura, de fractura irregular. Engobe: externo/ /aranja-acastanhado não muito escuro, de tom vivo, pouco espesso, pouco brilhante; interno/ idêntico ao externo. Cronologia: segunda metade do séc. V d.C. Proveniência: Villa de Santo André de Almoçageme, Quadrado VII, 2a Camada.

N. ${ }^{\circ} 6$ - MRS/SA/R/86/2003. Peça: fragmento de bordo de taça. Forma: provavelmente Hayes 1, variantes $\mathrm{B}$ ou C. Hayes apresenta apenas uma variante decorada (C) nesta forma, cuja decoração se assemelha com a do fragmento em estudo. Todavia, o bordo da nossa peça não se coaduna com o apresentado nessa variante, mas sim com o patente na variante B. Confrontar ainda e também a forma Hayes 3, variantes $\mathrm{F}$ ou $\mathrm{H}$ (HAYES, 1972, pp. 325-326 e M. DELGADO, 1975A, p. 278 e PI. LXXVI, n. ${ }^{\circ}$ 175). Diâmetro: $154 \mathrm{~mm}$ (interior). Pasta: laranja-acastanhada ligeiramente escura, de tom vivo, de grão fino, depurada, porosa, dura, de fractura irregular. Engobe: externo/ laranja-acastanhado ligeiramente escuro, pouco espesso, sem brilho, com uma faixa de tom mais vivo e mais brilhante localizada logo abaixo à curvatura que une o bordo à parede; interno/ idêntico ao externo, mas mais brilhante. Decoração: apresenta uma fieira de pequenas incisões obtidas por meio de guilhoché. Cronologia: segunda

Conimbriga, 40 (2001) 199-224 
metade do séc. V d.C. Proveniência:

de Santo André de Almoça-

geme, Quadrado X, I ${ }^{\text {a }}$ Camada.

N. 7 - MRS/SA/R/86/2298. Peça: fragmento de bordo de taça. Forma: Hayes 3, variante C. Diâmetro: $173 \mathrm{~mm}$ (exterior). Pasta: laranja-acastanhada ligeiramente escura, de grão médio, porosa, dura, de fractura irregular. Engobe: externo/ inexistente; interno/laranja-acastanhado, de tom vivo, pouco espesso, sem brilho. Decoração: apresenta cinco fieiras de incisões pouco profundas obtidas por meio de guilhoché. Cronologia: segunda metade do séc. V d.C. Proveniência: Villa de Santo André de Almoçageme, Testemunho entre os Quadrados XI e XII, 2a Camada.

N. 8 - MRS/SA/R/86/2469. Peça: fragmento de bordo de taça. Forma: Hayes 3, variante C. Diâmetro: $189 \mathrm{~mm}$ (exterior). Pasta: laranja-acastanhada ligeiramente escura, de grão médio, porosa, com impurezas, dura, de fractura irregular. Engobe: externo/ cinzento-acastanhado escuro, não muito espesso, sem brilho; interno/ laranja-acastanhado escuro, não muito espesso, sem brilho. Decoração: apresenta cinco fieiras de incisões, obtidas por meio de guilhoché. Cronologia: segunda metade do século $\mathrm{V}$ d. C. Proveniência: Villa de Santo André de Almoçageme, Quadrado XIII, Ia Camada.

N. 9 - MRS/SA/R/86/3504. Peça fragmento de bordo de taça. Forma: Hayes 3, provavelmente variante C. Diâmetro: $297 \mathrm{~mm}$ (exterior). Pasta: laranja-acastanhada clara, de grão muito fino, depurada, porosa, branda, de fractura regular. Engobe: externo/ inexistente; interno/ inexistente. Cronologia: segunda metade do século V d.C. Proveniência: Villa de Santo André de Almoçageme, 'Terreno B', Ia Camada.

N. 10 - MRS/SA/R/87/1. Peça: fragmento de bordo de taça. Forma: Hayes 3, variante B. Diâmetro: $280 \mathrm{~mm}$ (exterior). Pasta: laranja-acastanhada escura, de grão médio, pouco porosa, com algumas impurezas, dura, de fractura irregular. Engobe: externo/ laranja-acastanhado ligeiramente escuro, pouco espesso, pouco brilhante; intemo / laranja-acastanhado, de tom vivo, mas mais espesso que o externo, pouco brilhante. Decoração: apresenta três fieiras de incisões profundas separadas entre si por dois pequenos "cordões" salientes, obtidas 
por meio de guilhoché. Cronologia: segunda metade do século V d. C. Proveniência: Villa de Santo André de Almoçageme, Quadrado LI, 2a Camada.

N. 11 - MRS/SA/R/87/2. Peça: fragmento de bordo de taça. Forma: Hayes 3, variante C. Diámetro: $184 \mathrm{~mm}$ (exterior). Pasta: laranja-acastanhada, de torn vivo, de grão médio, porosa, dura, de fractura irregular. Engobe: externo/ laranja-acastanhado ligeiramente escuro, apresentando uma faixa mais avermelhada e mais escura logo antes do toro saliente em que termina o bordo, pouco espesso, sem brilho; interno/ laranja-avermelhado, pouco espesso, sem brilho. Decoração: apresenta seis fieiras paralelas de incisões com acentuações diferentes, obtidas por meio de guilhoché. Cronologia: segunda metade do século V d.C. Proveniência: Villa de Santo André de Almoçageme, Quadrado XI, 2a Camada.

N. ${ }^{\circ} 12$ - MRS/SA/R/89/13. Peça: fragmento de bordo de taça. Forma: Hayes 3, variante C. Diâmetro: $124 \mathrm{~mm}$ (exterior). Pasta: laranja-acastanhada, de tom vivo, de grão fino, depurada, porosa, dura, de fractura irregular. Engobe: externo/ laranja-acastanhado escuro, pouco espesso, sem brilho; interno/ idêntico ao externo. Cronologia: segunda metade do século V d.C. Proveniência: Villa de Santo André de Almoçageme, Quadrado LVII, 2a Camada.

N. ${ }^{\circ} 13$ - MRS/SA/R/89/11. Peça: fragmento de fundo de taça com pé em anel. Forma: Hayes 3, variante D. Pasta: castanha-alaranjada, de tom ligeiramente escuro, de grão médio, pouco porosa, dura, de fractura irregular. Engobe: externo/ laranja-acastanhado escuro, espesso, brilhante; interno/ idêntico ao extemo, mas mais espesso e brilhante. Cronologia: finais do século V d.C./ inícios do século VI d.C. Proveniência: Villa de Santo André de Almoçageme, Quadrado LVII, 2a Camada.

N. 14 - MRS/SA/R/89/30. Peça: fragmento de bordo de taça. Forma: Hayes 3, variante C. Diâmetro: $214 \mathrm{~mm}$ (exterior). Pasta: castanha-acinzentada escura, de grão médio, pouco porosa, dura, de fractura irregular. Engobe: externo/ castanho-alaranjado, pouco espesso, pouco brilhante; interno/ acastanhado escuro, espesso, brilhante. Cronologia: segunda metade do século V d.C. Proveniência: Villa de Santo André de Almoçageme, Quadrado LXXXIV, 2a Camada.

Conimbriga, 40 (2001) 199-224 
N. 15 - MRS/SA/R/89/31. Peça: fragmento de bordo de taça. Forma: Hayes 3, variante E Pasta: castanha-alaranjada ligeiramente escura, de grão médio, porosa, dura, de fractura irregular. Engobe: externo/ laranja-acastanhado escuro, pouco espesso, sem brilho; interno/ idêntico ao externo, mas de tom mais vivo. Decoração: apresenta uma fieira de incisões pouco profundas, obtida por meio de guilhoché. Cronologia: finais do século V d.C./ inícios do século VI d. C. Proveniência: Villa de Santo André de Almoçageme, Quadrado LXXXIV, 2a Camada.

N. ${ }^{\circ} 16$ - MRS/SA/R/89/14. Peça: fragmento de bordo de taça. Forma: Hayes 3, variante E Pasta: laranja-acastanhada, de tom vivo, de grão médio, porosa, dura, de fractura irregular. Engobe: externo/ laranja-acastanhado escuro, pouco espesso, sem brilho; interno/ inexistente. Decoração: apresenta duas fieiras de pequenas incisões pouco profundas, obtidas por meio de guilhoché. Cronologia: finais do século V d. C./ inícios do século VI d. C. Proveniência: Villa de Santo André de Almoçageme, Quadrado LXVII, 2a Camada.

N. ${ }^{\circ} 17$ - MRS/SA/R/89/32. Peça: fragmento de fundo de taça com pé em anel. Forma: Hayes 3, variante D. Diâmetro: $118 \mathrm{~mm}$ (interior, ao nível do anel). Pasta: laranja-acastanhada de tom claro, de grão fino, depurada, pouco porosa, dura, de fractura irregular. Engobe: externo/ laranja-acastanhado, de tom vivo, pouco espesso, sem brilho; interno/ castanho-alanranjado de tom escuro, pouco espesso, sem brilho. Cronologia: finais do século V d. C./ inícios do século VI d.C. Proveniência: Villa de Santo André de Almoçageme, Quadrado LXXXIV, 2a Camada.

N. ${ }^{\circ} 18$ - MRS/SA/R/89/33. Peça: fragmento de bordo de taça. Forma: Hayes 3, variante C. Diâmetro: $264 \mathrm{~mm}$ (exterior). Pasta: laranja-acastanhada clara, de grão médio, porosa, dura, de fractura irregular. Engobe: externo/ laranja-acastanhado, de tom vivo, pouco espesso, sem brilho; interno/ idêntico ao externo, mas de tom menos vivo. Cronologia: segunda metade do século $V$ d.C. Proveniência: Villa de Santo André de Almoçageme, Quadrado LXXXIV, 2a Camada.

N. ${ }^{\circ} 19$ - MRS/SA/R/89/35. Peça: fragmento de bordo de taça. Forma: Hayes 3, variante C. Diâmetro: $230 \mathrm{~mm}$ (exterior, ao nível 
mais saliente do perfil vertical). Pasta: acastanhada escura, de grão médio, pouco porosa, dura, de fractura irregular. Engobe: externo/ laranja-acastanhado, de tom escuro, pouco espesso, sem brilho, com listas de tonalidade mais clara; interno/ castanho escuro, espesso, sem brilho. Cronologia: segunda metade do século V d. C. Proveniência: Villa de Santo André de Almoçageme, Quadrado LXXXIV, 2a Camada.

N. ${ }^{\circ} 20$ - MRS/SA/R/89/12. Peça: fragmento de bordo de taça. Forma: Hayes 3, variante C. Diâmetro: $220 \mathrm{~mm}$ (exterior). Pasta: laranja-acastanhada clara, de grão fino, depurada, porosa, não muito dura, de fractura irregular. Engobe: externo/ inexistente; interno/ laranja-acastanhado claro, pouco espesso, sem brilho. Cronologia: segunda metade do século V d.C. Proveniência: Villa de Santo André de Almoçageme, Quadrado LXXXIV, 2a Camada.

N. ${ }^{\circ} 21$ - MRS/SA/R/89/34. Peça: fragmento de fundo de taça com pé em anel. Forma: Hayes 3, variante B. Diâmetro: $150 \mathrm{~mm}$ (interior, ao nível do anel). Pasta: acastanhada, de tom escuro, de grão médio, com impurezas, pouco porosa, dura, de fractura irregular. Engobe: externo/ castanho-alanranjado escuro, pouco espesso, sem brilho; interno/ idêntico ao externo, mas mais espesso. Cronologia: segunda metade do século V d.C. Proveniência: de Santo André de Almoçageme, Quadrado XCIV, 2a Camada.

N. ${ }^{\circ} 22$ - MRS/SA/R/93/1. Peça: fragmento de bordo de taça. Forma: Hayes 3, variante H. Diâmetro: $255 \mathrm{~mm}$ (exterior). Pasta: laranja-acastanhada, de tom escuro, de grão médio, pouco porosa, dura, de fractura algo rectilínea, com materiais não plásticos de médias dimensões. Engobe: externo/ castanho-alaranjado, de tom muito escuro, pouco espesso, sem brilho; interno/ laranja-acastanhado, de tom escuro, pouco espesso, sem brilho. Decoração: apresenta apenas na metade superior do bordo, três fieiras paralelas, mas irregulares, de incisões com acentuações diferentes, obtidas por meio de guilhoché. Cronologia: inícios do século VI d. C. (primeiro lustro). Proveniência: Villa de Santo André de Almoçageme, Terreno B, Vala 5, 2a Camada.

N. 23 - MRS/SA/R/93/2. Peça: fragmento de bordo de taça. Forma: Hayes 6. Diâmetro: $279 \mathrm{~mm}$ (exterior). Pasta: laranja-acastanhada, de tom claro e vivo, de grão fino, depurada, porosa, dura, de 
fractura irregular. Engobe: externo/ laranja claro e vivo, espesso, sem brilho; interno/ idêntico ao externo. Cronologia: inícios do século VI d.C. Proveniência: Villa de Santo André de Almoçageme, Terreno B, Vala 5, 2a Camada.

N. 24 - Peça descrita por M. G. P. MAIA (1978, p. 301, n 32), não tendo sido, contudo, incorporada nas colecções do Museu Regional de Sintra. O desenho que ora apresentamos é o inserto por aquela autora na página 306 (Est. II, n. ${ }^{\circ}$ 1): "FORMA - Hayes 3, variante C. PASTA - Laranja, um pouco avermelhada, de grão fino, com impurezas de pequenas dimensões. ENGOBE - $\mathrm{Na}$ face externa quase desapareceu, por desgaste, e praticamente não se nota a característica faixa mais escura, junto ao bordo. $\mathrm{Na}$ face interna é laranja avermelhado, pouco espesso e não muito alisado. DECORAÇÃO - Três linhas de incisões finas na zona quase vertical, junto ao bordo externo. CRONOLOGIA A variante $\mathrm{C}$ da forma Hayes 3 está datada, de acordo com a estratigrafía da Ágora de Atenas, de 406-475 d.C. REFERÊNCIA Superfície." Proveniência: Villa de Cabanas (São Marcos).

N. 25 - MRS/SM/R/79/13. Peça: fragmento de bordo de taça. Forma: Hayes 3, variante C. Diâmetro: $320 \mathrm{~mm}$ (exterior). Pasta: laranja-acastanhada, de tom vivo, de grão médio, pouco porosa, com impurezas, dura, de fractura irregular. Engobe: externo/ laranja-acastanhado ligeiramente escuro, pouco espesso, sem brilho; interno/ laranja-avermelhado ligeiramente escuro, pouco espesso, pouco brilhante. Decoração: apresenta três fieiras paralelas de incisões com acentuações diferentes, obtidas por meio de guilhoché. Cronologia: segunda metade do século V d.C. Proveniência: Villa de Cabanas (São Marcos), Superfície.

N. 26 - MRS/SM/R/79/399. Peça: fragmento de bordo de taça. Forma: Hayes 3, variante C. Diâmetro: $223 \mathrm{~mm}$ (exterior). Pasta: laranja-acastanhada clara, de grão médio, porosa, com impurezas, dura, de fractura irregular. Engobe: externo/ praticamente inexistente, mas deixando entrever, no entanto, uma cor castanha-acinzentada, de tom escuro. Com laivos mais claros em algumas zonas, pouco espesso, sem brilho; interno/ laranja-acastanhado, de tom vivo, mais espesso que o externo, sem brilho. Decoração: apresenta três fieiras paralelas de incisões obtidas por meio de guilhoché. Cronologia: segunda metade 
do século V d.C. Proveniência:

de Cabanas (São Marcos),

Quadrado G/ 6, 2a Camada.

N. ${ }^{\circ} 27$ - MRS/SM/R/79/400. Peça: fragmento de bordo de taça. Forma: Hayes 3, variante C. Diâmetro: $280 \mathrm{~mm}$ (exterior). Pasta: laranja-acastanhada, de tom escuro, de grão médio, pouco porosa, com impurezas, dura, de fractura irregular. Engobe: externo/ inexistente; interno: laranja-acastanhado, de tom vivo, pouco espesso, sem brilho. Cronologia: segunda metade do século V d.C. Proveniência:Villa de Cabanas (São Marcos), Quadrado G/ 6, 2a Camada.

N. 28 - MRS/SM/R/79/492. Peça: fragmento de bordo de taça. Forma: Hayes 3, variante E. Diâmetro: $287 \mathrm{~mm}$ (exterior). Pasta: laranja-acastanhada ligeiramente escura, de grão médio, pouco porosa, dura, de fractura irregular. Engobe: externo/ inexistente; interno/ acastanhado, ligeiramente escuro, pouco espesso, sem brilho. Decoração: apresenta duas fieiras paralelas de incisões, separadas entre si por um pequenino cordão saliente e obtidas por meio de guilhoché. Cronologia: finais do século V d.C./ inícios do século VI d. C. Proveniência: Villa de São Marcos, Quadrado G/ 6, 2. ${ }^{\text {a Camada. }}$

N. ${ }^{\circ} 29$ - MRS/AR/R/86/117. Peça: fragmento de bordo de taça. Forma: Hayes 3, variante E. Diâmetro: $239 \mathrm{~mm}$ (exterior). Pasta: laranja-acastanhada ligeiramente escura, de grão médio, porosa, dura, de fractura irregular. Engobe: externo/ laranja-acastanhado escuro, pouco espesso, pouco brilhante; interno/ laranja-acastanhado, mas mais claro que o externo, de tom vivo, pouco espesso, sem brilho. Decoração: apresenta duas fieiras paralelas de incisões profundas, separadas entre si por um pequenino cordão saliente e obtidas por meio de guilhoché. Cronologia: finais do século V d.C./ inícios do século VI d.C. Proveniência: Estação Romana de Armés, Superfície.

N. 30 - MRS/CCL/R/89/1. Peça: fragmento de bordo de taça. Forma: Hayes 3, variante C. Diâmetro: $275 \mathrm{~mm}$ (exterior). Pasta: laranja-acastanhada, de tom escuro, de grão médio, com algumas impurezas visíveis, pouco porosa, dura, de fractura irregular. Engobe: externo/ laranja-acastanhado, de tom escuro, pouco espesso, sem brilho; interno/ idêntico ao externo, mas de tom mais claro. Crono-

Conimbriga, 40 (2001) 199-224 
logia: segunda metade do século V d.C. Proveniência: Villa do Casal de Colaride, Superfície.

N. ${ }^{\circ} 31$ - MRS/CCL/R/90/1. Peça: fragmento de bordo de taça. Forma: Hayes 5, variante A. Diâmetro: $138 \mathrm{~mm}$ (interior). Pasta: laranja-acastanhada, de tom claro, de grão fino, depurada, pouco porosa, dura, de fractura irregular. Engobe: externo/ laranja-acastanhado claro, de tom vivo, com faixas mais escuras (manchas de cozedura), pouco espesso, sem brilho; interno/ idêntico ao externo, mas mais claro e sem manchas de cozedura. Cronologia: segunda metade do século V d.C. (entre 460 e 500 d.C.). Proveniência: Villa do Casal de Colaride, Superfície.

\section{BIBLIOGRAFIA}

Alarcão, A. M., 1966, "Bref Aperçu sur la céramique romaine trouvée à Bracara Augusta (Portugal)", Rei Cretariae Fautorum, Acta VIII, pp. 45-53.

Alarcão, J., 1968, “Une Coupe à Fond d' Or Découverte à Farrobo, Portugal”, Journal of Glass Studies, X, pp. 74-75.

- 1974, Portugal Romano, Lisboa, p. 152, foto n. 78 e p. 265.

- 1975, "Céramique à glaçure plombifère", in A Propos des Céramiques de Conimbriga, Conimbriga, XIV, Coimbra, pp. 100 e 101 e PI. XVII.

— 1976, "Céramiques à glaçure plombifère", Fouilles de Conimbriga, VI, Paris, pp. 39-42 e PI. XXXII.

Alcock, L., 1964, "Dinas Powys ”, Archeology, vol. 17, pp. 104-111.

AlföLdy, G., 1977, “L' Onomastique de Tarragone”, L' Onomastique Latine, C. N. R. S., Paris, pp. 293-295.

Almagro Corbea, M., 1966-1967, "Ajuar de la Sepultura ao de la Necropolis de Farrobo. Nuevas Aportaciones para el Estudio del (Aljustrel)", Arquivo de Beja, XXIII-XXIV, pp. 213-223.

Arruda, A. M., 1993, “A Late Roman C Ware”, Historia de Portugal, dir. por João Medina, vol. I, p. 308.

BarRón, A. U., 1992, "Cerámica Importada en Gerasa (Yaras, Jordania): el lote de las Excavaciones del Macellum”, Caesar augusta, n. ${ }^{\circ}$ 69, pp.115-181.

Beltrán Lloris, M., 1978, Cerámica Romana: Tipología y Clasificación, p. 128, Saragoça.

- 1990, Guía de la Cerámica Romana, pp. 279-281, Saragoça.

Bourgeois, A. e Mayet, F., 1991, "Les Sigillées Tardives du Moyen-Orient", Fouilles de Belo, VI, Madrid, pp. 373-376 e Pis. CXVI-CXX.

Cardoso, G. e Encarnação, J. d $\backslash 1998$, "Villa Romana de Freiría. Campanhas de 1997 e 1998”, Al-madan, Almada, pp. 181-182. 
Carvalho, T. P., 1998, “A Terra Sigillata de Boelhe”, Cadernos do Museu de Penaflel, n. ${ }^{\circ}$, p. 78 , fig. 4.

Comfort, H., 1961, "Roman Ceramics in Spain: an Exploratory Visit", Archivo Español de Arqueologia, vol. XXXII.

Coutinho, H., 1997, Terra Sigillata Clara do Montinho das Laranjeiras - 1990 e 1991, Alcoutim, ed. da C. M. de Alcoutim.

Delgado, M., 1971, Dez Anos de Actividade Arqueológica em Portugal 1960-1970, Coimbra, pp. 32 e 33.

— 1975B, "Sigillées Claires - Late Roman C", in A Propos des Céramiques de Conimbriga, Conimbriga, vol. XIV, (A Propos des Céramiques de Conimbriga), Coimbra, pp. 147-148 e PI. XII, ${ }^{\circ} 1$ a 8.

— 1988, "Contribuição para o estudo das cerâmicas romanas tardias do Médio Oriente", Cadernos de Arqueologia, Série II, vol. 5, pp. 35-45 e Ests. I, II e III.

- 1992, "Cerâmicas Tardias de Mértola Originárias do Médio Oriente", Arqueologia Medieval, Porto, vol. 1, pp. 125-133.

— 1975A, "Sigillée Late Roman C", Fouilles de Conimbriga, t. IV, Paris, pp. 285 - 291,308 - 313 ep. 334.

Dias Dıogo, A. M., 1984, "O Material Romano da Ia Campanha de Escavações na Alcáçova de Santarém”, Conimbriga, XXIII, pp. 111-141, e Ests. I a IV.

Dias Diogo, A. M. e TRINDAde, L., 1999, "Ânforas e sigillatas tardias (claras, foceenses e cipriotas) provenientes das escavações de 1966/67 do teatro romano de Lisboa", Revista Portuguesa de Arqueologia, Lisboa, vol. 2, n. ${ }^{\circ}$ 2, pp. 83-95.

Empereur, J.-Y. e Picon, M., 1986, “À propos d'un nouvel atelier de «Late Roman C Ware»”, Figlina, n 7, pp. 143-147.

Encarnação, J. d', 1984, “A População Romana de Tróia”, Património, n. 2, pp. 15-17.

FÉvrier, P.-A., 1976, "De Sétif à Conimbriga en Passant par $V$ Orient", Conimbriga, vol. XV, pp. 64-72.

Freire de ANDRADE, R., 1963, "Sepultura número 20 do Cemitério Lusitano-Romano do Farrobo", Arquivo de Beja, XIX-XX, pp. 115-123.

Freire de Andrade, R. e Veiga Ferreira, O., 1967, "Um vaso Lusitano-Romano com Vidrado de Chumbo, encontrado no Monte do Farrobo, Rio de Moinhos", Revista de Guimarães, LXXVII, pp. 109-114.

Gorges, J. G., 1979, Les Villas Hispano-Romaines, París.

Gonçalves Guimarães, J. A., 1992, "Escavações Arqueológicas na Igreja do Bom Jesus de Gaia", Actas da IV Reunião de Arqueologia Cristã Hispânica, ed. do Instituí d'Estudis Catalans, da Universidade de Barcelona e da Universidade Nova de Lisboa, pp. 107-109.

- 1993, Roteiro Arqueológico de Vila Nova de Gaia, ed. do Núcleo Museológico de Arqueologia, Câmara Municipal de Vila Nova de Gaia, Vila Nova de Gaia.

- 1995, Gaia e Vila Nova na Idade Média - Arqueologia de uma área ribeirinha, Porto, Universidade Portucalense.

Gonçalves Guimarães, J. A. e Pinto, C. T., no prelo, "Cerâmica Arqueológica de Gaia. - Análise de elementos de uma sequência de longa duração", Actas do III Congresso de Arqueologia Peninsular, Vila Real. 
Hayes, J. W., 1972, Late Roman Pottery, Londres, pp. 323 a 370, 459 e 460.

- 1980, Supplement to Late Roman Pottery, Londres, pp. 525-527.

Horta Pereira, M. A., 1970, "O Dolium Cinerário, com Skyphos vidrado a verde, da Necrópole de Paredes (Alenquer)", Conimbriga, IX, Coimbra, pp. 45-74.

JÁrRega Domínguez, R., 1991, Cerâmicas Finas Tardorromanas y dei Mediterraneo Oriental en España. Estado de la Cuestión, Madrid, pp. 85-87.

Jodin, A. e Ponsich, M., 1960, "La Céramique Estampée du Maroc Romain", Bulletin d'Archeologie Marocaine, t. IV, Casablanca, pp. 287-315.

LoPes, V., 1993, "Materiais Arqueológicos", Catálogo do Museu de Mértola / Basílica Paleocristã, pp. 86-88.

MalA, M. G. P., 1974, "Cerámica Fina Oriental de Tróia de Setúbal: «Late Roman C Ware»", Actas do III Congresso Nacional de Arqueologia, 1973, Porto, pp. 333341.

— 1978, "Contributos para as Cartas de Distribuição em Portugal da «Sigillata Luzente» e da «Late Roman C Ware»", Actas das III Jornadas Arqueológicas/1977, Lisboa, pp. 295-307.

Martí i Garcia, C., 1980, “500é Ani versari de 1' Alliberament deis Lligams Senyorials deis Castells de Burriac i Mataró”, Quaderns de Prehistoria i Arqueologia del Maresme, 10, pp. 289-312.

MAYet, F. e Picon, M., 1986, "Une sigillée phocéenne tardive «Late Roman C Ware» et sa diffusion en Occident", Figlina, n. ${ }^{\circ}$, pp. 129-143.

Mayet, F., et alii, 1990, Les Villas Romaines de São Cucufate (Portugal), Paris.

MAYet, F., et alii, 1994, Un Grand Complexe Industriei à Tróia (Portugal), Paris, p. 47 e Fig. $29, n^{\circ} 119-121$.

MÉndez ORTIZ, R., 1983-1984, “Cerámica tipo Late Roman «C» en Cartagena", Pyrenae, Barcelona, pp. 147-156 e Láms.l e 2.

Miranda, J. A. e Encarnação, G., 1998, "Villa Romana da Quinta da Bolacha. Campanha de Abril/Maio de 1997", Relatórios - 4, ed. do Gabinete de Arqueologia Urbana, Amadora.

Miranda, J., et alii, 1999, Carta Arqueológica. Do Paleolítico ao Romano, Amadora.

Nieto, J. F., 1984, “Algunos datos sobre las importaciones de cerámica «Phocaean Red Slip Ware» en la Península Ibérica", British Archaeological Reports, 'International Series, 193, Papers in Iberian Archaeology', Parte II, pp. 430-459.

Nolen, J. U. S., 1988, “A Villa Romana do Alto do Cidreira (Cascais)”, Conimbriga, XXVII, pp. 61-140, sobretudo p. 87 e Est. IV.

- 1994, Cerâmicas e Vidros de Torre de Ares (Balsa), pp. 102, 221 e Est. 22, n. ${ }^{\circ} \mathrm{sc}-58$.

Nunes Ribeiro, F., 1957, "Breve Nota sobre a Estação Romana de Lobeira Grande (Beja)", Publicações do XIII Congresso Luso-Espanhol para o Progresso das Ciências, VIII, Coimbra, pp. 453-459.

OrLandis, J., 1967, Historia del Reino Visigodo Español, Madrid.

PÁz Peralta, J. A., 1991, Cerámica de Mesa Romana de los Siglos 111 al VI d. C. En la Provincia de Zarazoza (Terra sigillata hispánica tardía, African red slip ware, sigillata gálica tardía y Phocaean red slip ware), Saragoça. 
Pereira, M. A. G., 1971, "Fragmento de vaso vidrado a verde da estação romana de Tróia (Setúbal)”, O Arqueólogo Portugués, Lisboa, Série III, vol. V, pp. 145-154.

Quaresma, J. C., 1999, "Terra Sigillata Africana e Foceense Tardia das escavações recentes de Mirobriga (Chãos Salgados, Santiago do Cacém”, Revista Portuguesa de Arqueologia, Lisboa, vol. 2, n. ${ }^{\circ}$ 2, pp. 69-81.

1999A, "Terra Sigillata Africana, Hispánica, Foceense Tardia e Cerámica Africana de Cozinha de Mirobriga (Santiago do Cacém)", Conimbriga, vol. XXXVIII, pp. 137-200.

QuinteIRA, A. J. F., 1984, "Duas peças de vidrado a verde achadas em Conimbriga", Conimbriga, XXIII, pp. 103-110.

Reynolds, P., 1987, El Yacimiento Tardorromano de Lucentum (Benalua-Alicante): Las Cerámicas Finas, Alicante, pp. 109-121.

Ribeiro, J. C., no prelo, "Contributos para um Estudo Demográfico do Municipio Olisiponense durante a Romanidade: Movimentos Migratorios e Elementos Externos", Sintria, no prelo.

Sepúlveda, E., Sousa, E. M. e Sousa, V. C., no prelo, "Cerâmicas Finas Romanas do Museu Municipal Leonel Trindade (Torres Vedras) - II. A Terra Sigillata", Revista de Arqueologia, ed. da Assembleia Distrital de Lisboa.

SoEIRo, T., 1985-1986, "A suvidade de São Mamede de Recezinhos. Campanha de Escavações de 1985", Boletim Municipal de Cultura, Penafiel, pp. 15-32.

SousA, E. M., 1989, "Incidência da «Terra Sigillata» no Contexto Arqueológico de urna Villa Áulica dos Agri Olisiponenses - O caso do 'Terreno A' das Ruinas Romanas de Santo André de Almoçageme (Freg. de Colares, Cone. de Sintra)”, Actas do Seminário: Espaço Rural na Lusitânia, Tomar, pp. 85-91.

- 1992, "Presença de «Terra Sigillata» Clara com Decoração de Relevos Aplicados na Villa de Santo André de Almoçageme (freg. de Colares, cone, de Sintra)", Setúbal Arqueológica, vol. IX-X, pp. 385-390.

- 1992A, "Terra Sigillata Hispânica Tardia da Villa de Santo André de Almoçageme (Colares, Sintra)", Artefactos, vol. I, Lisboa, pp. 16-21.

- 1993-1994, "Cerâmica Vidrada Romana Proveniente de Tróia de Setúbal”, Conimbriga, vols. 32-33, pp. 359-369.

Tavares da Silva, C., Coelho-Soares, A. e Soares, L, 1987, "Nota sobre o material anfórico da Foz do Arade (Portimão)", Setúbal Arqueológica, vol. VIII, pp. 203219.

Trindade, L. e DiAs Diogo, A. M., 1996, "Materiais provenientes do sitio romano da Comenda", Al-madan, Almada, 20 Série, vol. 5, pp. 7-12.

WAGgè, F. O., 1933, "The American Excavations in the Athenean Agora. First Report: The Roman and Bysantine Pottery", Hesperia, II. - 1948, Antioch-on-the-Orontes, t. IV, I, Princeton, pp. 1-45. 


\section{NOTAS:}

* O presente artigo constitui a terceira versão (inédita) do trabalho entregue, em 1988, para publicação na Revista Sintria [vol. I (2)].

** Todas as peças analisadas integraram, outrora, as colecções do antigo Museu Regional de Sintra. Hoje, permanecem conservadas no Museu Arqueológico de São Miguel de Odrinhas.

*** Agradecemos ao Dr. Eurico de Sepúlveda a preciosa ajuda que nos deu no decurso do presente trabalho, pois sem ela teria sido mais difícil a sua concretização. Agradecemos-lhe também o desenho do Mapa.

**** Qs desenhos das peças apresentadas devem-se a Paulo Jorge Faustino. 


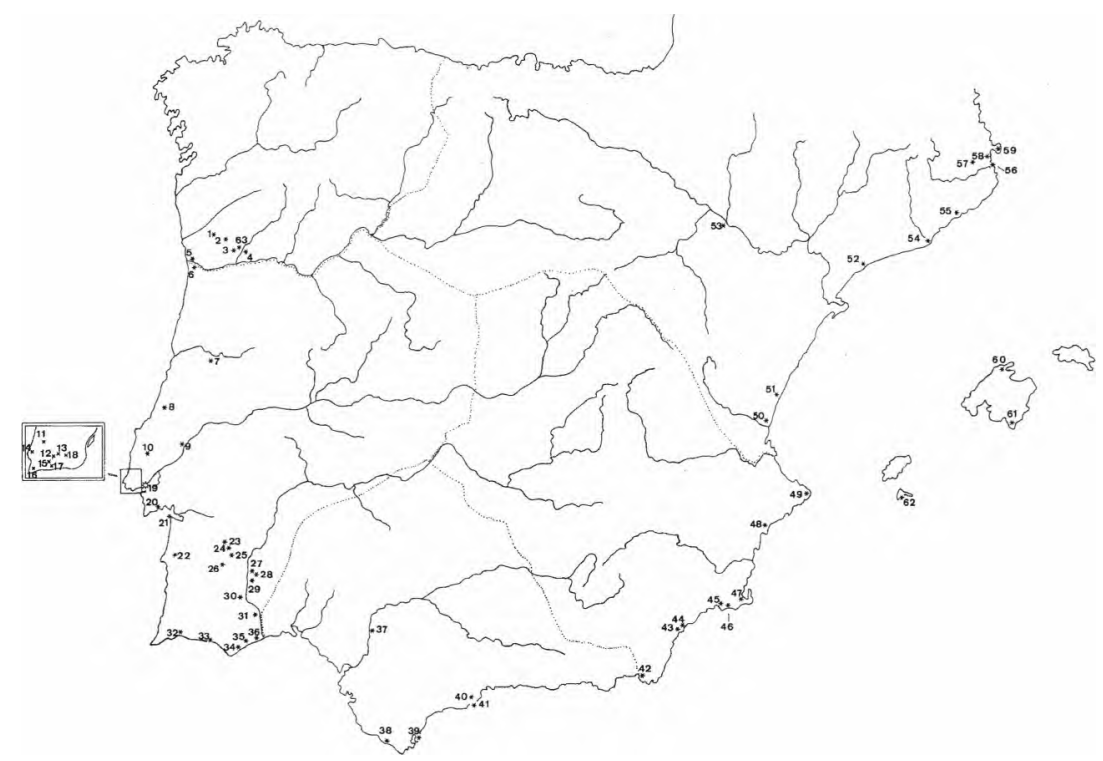

Mapa de Distribuição da Cerâmica Foceense Tardia ("Late Roman C Ware") na Península Ibérica: 1 - Bracara Augusta; 2 - Falperra (Nogueira, Braga); 3 - São Mamede de Recezinhos (Penafiel); 4 - Freixo (Marco de Canavezes); 5 - Portus 6 Cale (Vila Nova de Gaia); 7 - Conimbrigal 8 - Póvoa de Cós (Alcobaça); 9 - Scallabis', 10 - Villa da Aldeia do Penedo (Runa, Torres Vedras); 11 - Armés (Terrugem, Sintra); 12 - Villa do Casal de Colaride (Cacém, Sintra); 13 - Villa de Cabanas (São Marcos, Cacém, Sintra); 14- Villa de Santo André de Almoçageme (Colares, Sintra); 15- Casal do Clérigo (Cascais); 16- Villa do Alto do Cidreira (Carrascal de Alvide, Cascais); 17 - Villa de Freiria (São Domingos de Rana, Cascais); 18 - Villa da Quinta da Bolacha (Falagueira-Venda Nova, Amadora); 19 - Olisipol 20 - Comenda; 21 - Tróia de Setúbal; 22 - Mirobriga 23 - Alvito; 24 - São Cucufate (Vidigueira); 25 - Monte da Cegonha (Vidigueira); 26 - Represas (Beja); 27 - Cidade das Rosas (Herdade das Barrosas, Serpa); 28 - Horta de D. Maria (Serpa); 29 - Monte da Salsa (Brinches, Serpa); 30 - Myrtilis', 31 - Montinho das Laranjeiras (Alcoutim, Mértola); 32 - Cerro da Vila (Vilamoura, Quarteira); 33 - Loulé Velho (Quarteira, Loulé); 34 - Foz do Arade (Portimão); 35 - Marim (Quelfes, Olhão); 36 - Balsa (Torre de Ares, Luz, Tavira); 37 - Sevilha; 38 - Baelo| 39 - Carteia; 40 - Cártama (Málaga); 41 Torreblanca del Sol (Fuengirola, Málaga); 42 - Cerro de Montroy (Villaricos, Almería); 43 - Aguilas (Cartagena); 44 - Isla del Fraile (Aguilas, Cartagena); 45 Puerto de Mazarrón (Cartagena); 46 - La Azhoia (Mazarrón, Cartagena); 47 Carthago Nova; 48 - Lucentum; 49 - Punta del Arenal (Jávea, Alicante); 50 Valência; 51 - Saguntum; 52 - Tarraco; 53 - Caesar augusta', 54 - Barcino; 55 Mataró (Barcelona); 56 - Torroella de Montgrí (Barcelona); 57 - Camós (Barcelona); 58 - Emporion $\mid 59$ - Rosas (Barcelona); 60 - Pollentia', 61 - Colonia de Sant Jordi (Maiorca); 62 - Formentera (Ilha de Formentera, Baleares); 63 - Boelhe (Penafiel). 
EsT. I

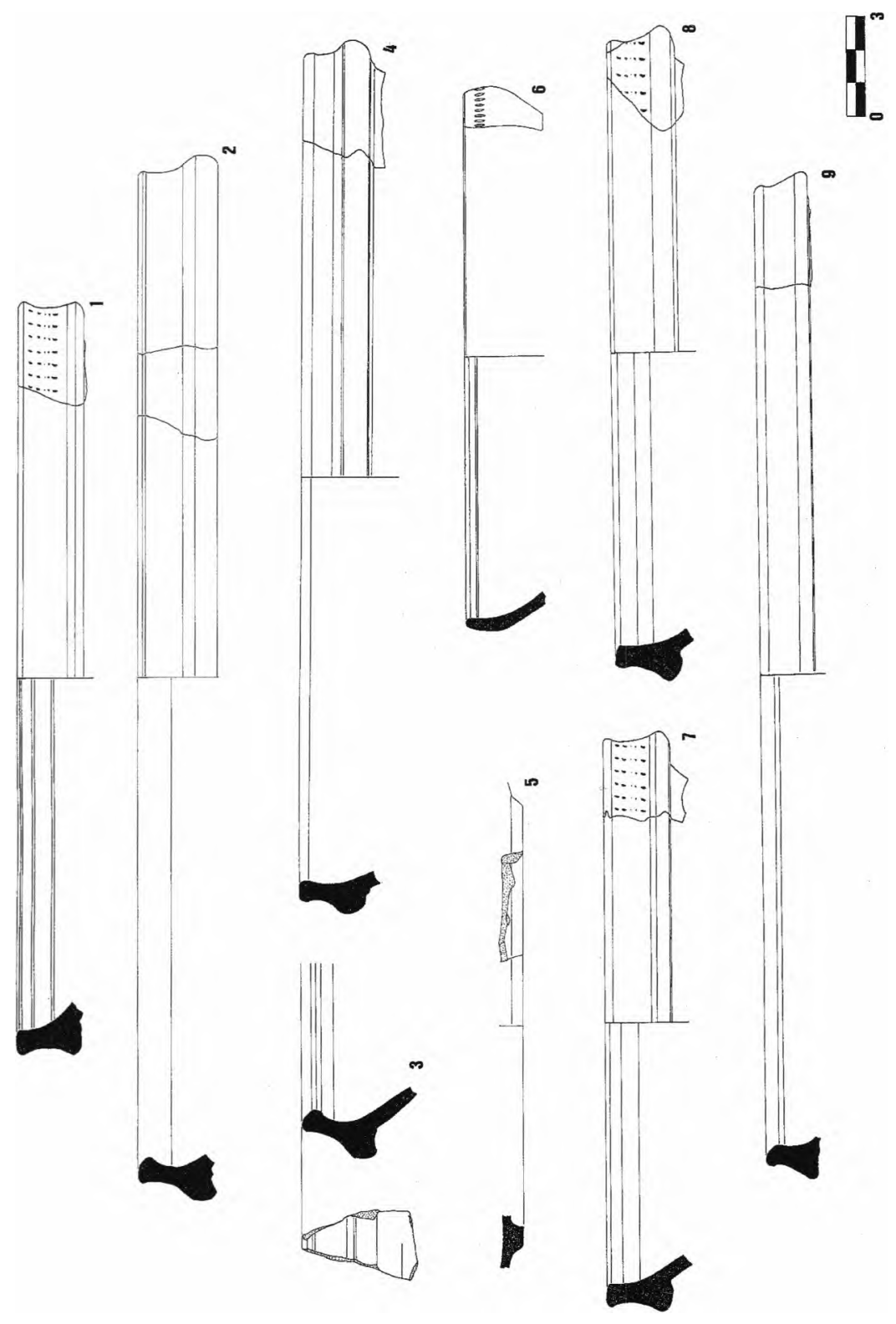



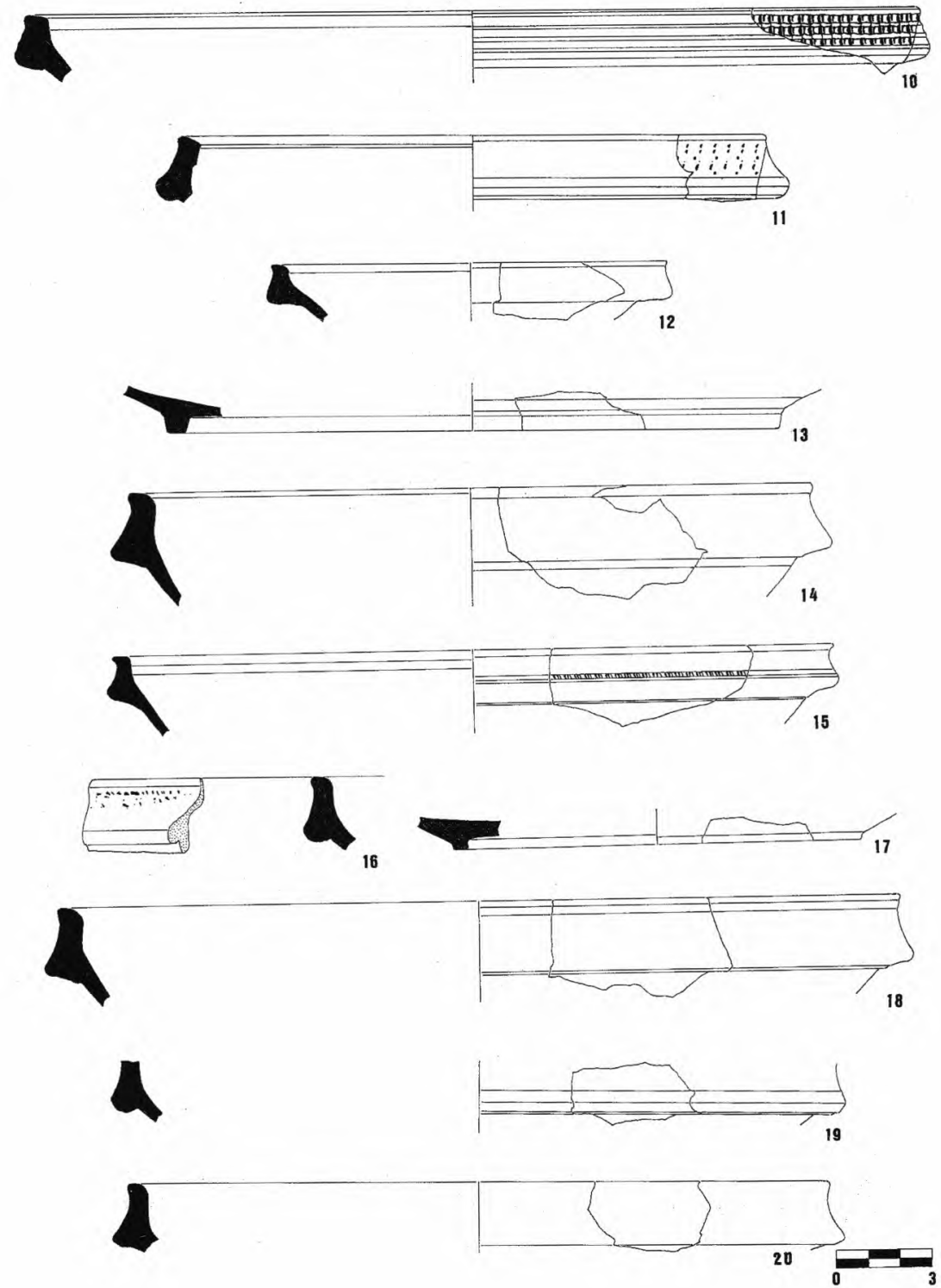


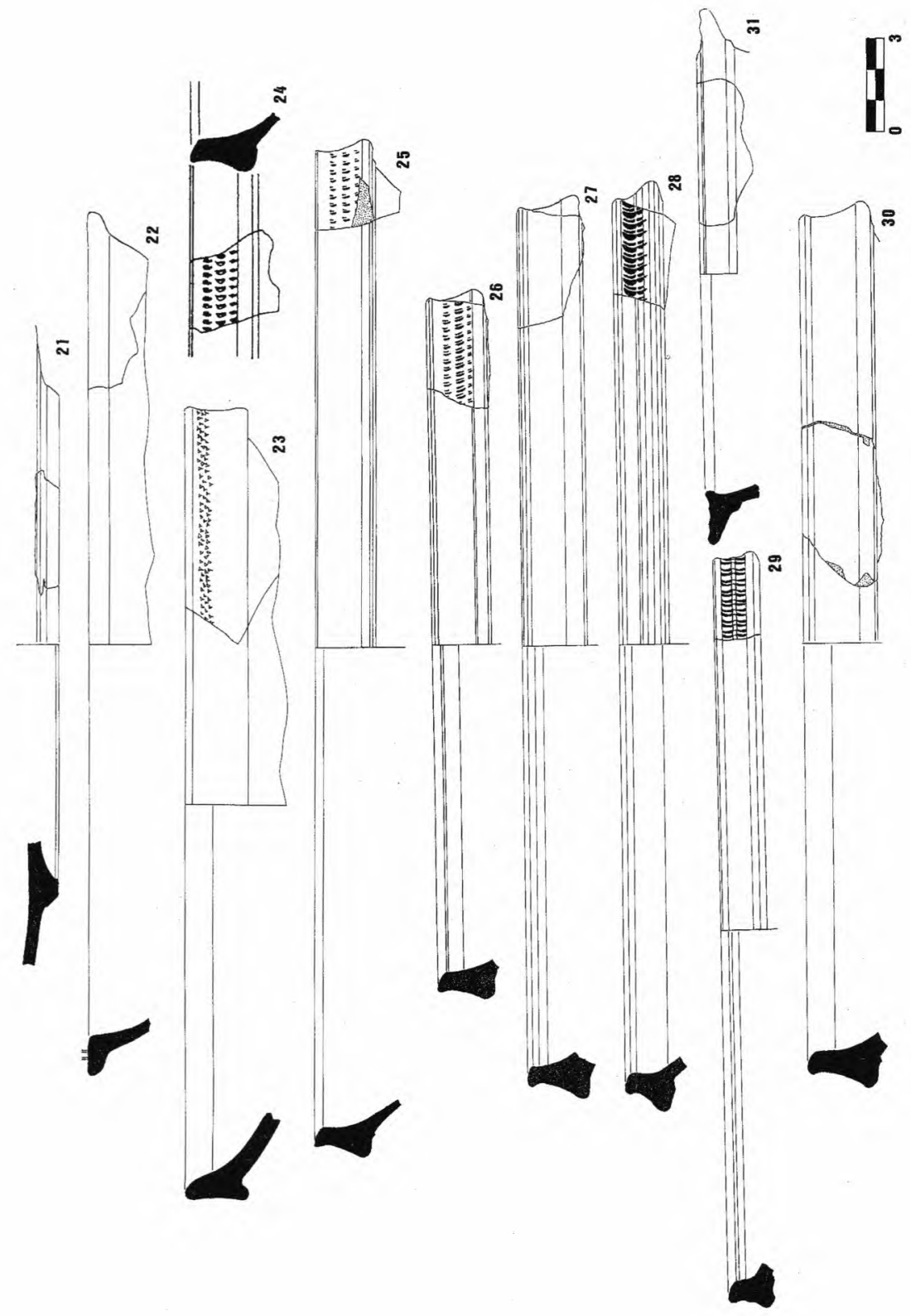

